\title{
Effect of Stacking Fault Precipitation on Hot Deformation of Austenitic Stainless Steel*
}

\author{
By Kazuhito KAMEI,** Yasuhiro MAEHARA** and Yasuya OHMORI**
}

\section{Synopsis}

The hot deformation characteristics of $\mathrm{Nb}$-bearing austenitic stainless steel have been studied by means of tensile test and transmission electron microscopy in reflection to the stacking fault precipitation of $\mathrm{NbC}$. Tensile tests were carried out at temperature ranging from 823 to $1173 \mathrm{~K}$ at an initial strain rate of $2.1 \times 10^{-4} \mathrm{~s}^{-1}$.

Although the yield strength of the solution-treated specimen was quite low, remarkable work hardening occurred at temperature ranging from 1023 to $1123 \%$. In this temperature region, a deep ductility trough accompanied by intergranular ductile fracture was also observed. This can be explained in terms of the dynamic precipitation of $\mathrm{NbC}$ within the grains as well as on the grain boundaries.

In the aged specimen, on the other hand, the yield strength was much higher than that of solution treated, but the work hardening was less significant. Such a high yield strength is probably due to the refinement of the average effective grain size, i.e., an austenite grain being separated into several regions by the hard platelets of stacking faults with fine $\mathrm{NbC}$ particles. The ductility trough in this case was rather shallow because of the reduction of dynamic $\mathrm{NbC}$ precipitation.

At temperatures above $1123 \mathrm{~K}$, the ductility of the solution-treated specimen increased with increasing deformation temperature, but that of the aged specimen was largely reduced. This ductility loss could arise from local dynamic recrystallization in the vicinity of grain boundaries.

\section{Introduction}

Hot ductility of the solution treated Nb-bearing austenitic stainless steels is markedly reduced by the slow strain rate deformation at temperatures around $1000 \mathrm{~K}$. This is explained in terms of the precipitation of coarse $\mathrm{M}_{23} \mathrm{C}_{6}$ and $\mathrm{NbC}$ particles on the grain boundaries and fine $\mathrm{NbC}$ particles within the grains with the formation of Precipitation Free Zone's (PFZ's) along the boundaries. In this case, the mobile dislocations induced mainly at the grain boundaries during hot deformation will be trapped by dynamically precipitated $\mathrm{NbC}$ particles within the grains and the mobility of dislocations will be significantly reduced. Thus the fresh dislocations must nucleate at the boundaries in order to continue further deformation. This process will result in the strain concentration within the soft PFZ's along the boundaries and microvoids initiating by the decohesion of the precipitate/austenite interfaces at the boundaries will coalesce, resulting in intergranular ductile fracture. ${ }^{1,2)}$

The static precipitation of fine $\mathrm{NbC}$ particles also occurs during aging at $973 \mathrm{~K}$ with the simultaneous formation of extrinsic stacking faults. This phenomenon has been well known as "stacking fault precipitation ", and the formation mechanism and its effects on the mechanical properties have been the subjects of numerous studies. ${ }^{4-11)}$ In the hot deformation of the specimen aged in such a condition, however, the dynamic precipitation of $\mathrm{NbG}$ particles will be largely suppressed and the deformation characteristics will markedly differ from those of solution treated materials.

In the present study, therefore the effects of stacking fault precipitation of $\mathrm{NbG}$ on the hot deformation properties of austenitic stainless steel have been examined in comparison with those of dynamic precipitation.

\section{Experimental Procedures}

The chemical composition of the steel used is given in Table 1. The steel was melted in a $20 \mathrm{~kg}$ vacuum induction furnace. The ingot was forged and rolled into the bars of $20 \mathrm{~mm}$ diameter. They were solution treated at $1523 \mathrm{~K}$ for $30 \mathrm{~min}$ and quenched into water. Some of the solution treated bars were aged at $973 \mathrm{~K}$ for $100 \mathrm{~h}$. From both the solution treated and the aged bars, tensile specimens were machined in the direction parallel to the rolling direction. The gauge length, the diameter and the fillet radius of the tensile specimens were 40, 6 and $5 \mathrm{~mm}$, respectively. Hot tensile tests were carried out by using Instron-type tensile machine in a flowing argon atmosphere. The specimens were heated at a rate of $100 \mathrm{~K} \cdot \mathrm{min}^{-1}$ to the temperatures ranging from 823 to $1173 \mathrm{~K}$ in the infrared imaging furnace attached to the tensile machine. After keeping for $10 \mathrm{~min}$, they were isothermally pulled at a constant crosshead speed (the initial strain rate was $2.1 \times$ $10^{-4} \mathrm{~s}^{-1}$ ) until the final fracture occurred.

The fractured specimens were examined by means of transmission electron microscopy (TEM) and scanning electron microscopy (SEM). Thin foils were prepared by a conventional twin jet electropolishing method with using the disk machined from the fracture specimens near the fracture surface, and were observed in a Hitachi $\mathrm{H}-700 \mathrm{H}$ microscope operating at $200 \mathrm{kV}$.

Table 1. Ghemical compsition of the material used. (wt\%)

\begin{tabular}{cccccccc}
\hline $\mathrm{C}$ & $\mathrm{Si}$ & $\mathrm{Mn}$ & $\mathrm{P}$ & $\mathrm{S}$ & $\mathrm{Ni}$ & $\mathrm{Cr}$ & $\mathrm{Nb}$ \\
\hline 0.048 & 0.50 & 1.35 & 0.004 & 0.005 & 11.03 & 18.59 & 0.46 \\
\hline
\end{tabular}

\footnotetext{
* Originally published in Tetsu-to-Hagané, 71 (1985), 978, in Japanese. English version received on June 26, 1985; accepted in the final form on September 13, 1985. (C) 1986 ISIJ

** Central Research Laboratories, Sumitomo Metal Industries, Ltd., Nishinagasu-Hondori, Amagasaki 660.
} 


\section{Experimental Results}

\section{Tensile Properties}

Figure 1 illustrates stress-strain curves in the solution treated and the aged specimens. Although the solution treated specimens exhibit rather low yield stress, significantly large work hardening occurs during the following deformation in the temperature range from 823 to $1023 \mathrm{~K}$. Such a high work hardening rate decreases with raising deformation temperature above $1073 \mathrm{~K}$ and no work hardening is observed at $1173 \mathrm{~K}$. The yield strengths of the aged specimens are higher than those of the solution treated, but the work hardening rates of the formers are much smaller than those of the latters. It should be noted that the serrations of the stress-strain curves can clearly be observed in the case of deformation temperatures between $923 \mathrm{~K}$ and $823 \mathrm{~K}$ in both cases.

Variations of $0.2 \%$ proof stress (YS), the ultimate tensile stress (UTS) and the reduction of area (RA) with deformation temperature are illustrated in Fig. 2. The YS's of the aged specimens are much higher than those of the solution treated but the difference between them decreases with raising the deformation temperature.

Although the RA's of both the specimens decrease with raising the deformation temperature up to $1000 \mathrm{~K}$, the decreasing rate for the aged specimens is much smaller than that for the solution treated. The RA of the as-solution-treated specimens increases gradually with deformation temperature above $1000 \mathrm{~K}$ while that of the aged shows the maximum value at $1073 \mathrm{~K}$ and then decreases with the further increase of deformation temperature.

Figure 3 shows variations of work hardening rate at $4 \%$ strain, $(\partial \sigma / \partial \varepsilon)_{\varepsilon=0.04}$, with deformation temperature. The work hardening rate of the solution treated specimen is much larger than that of the

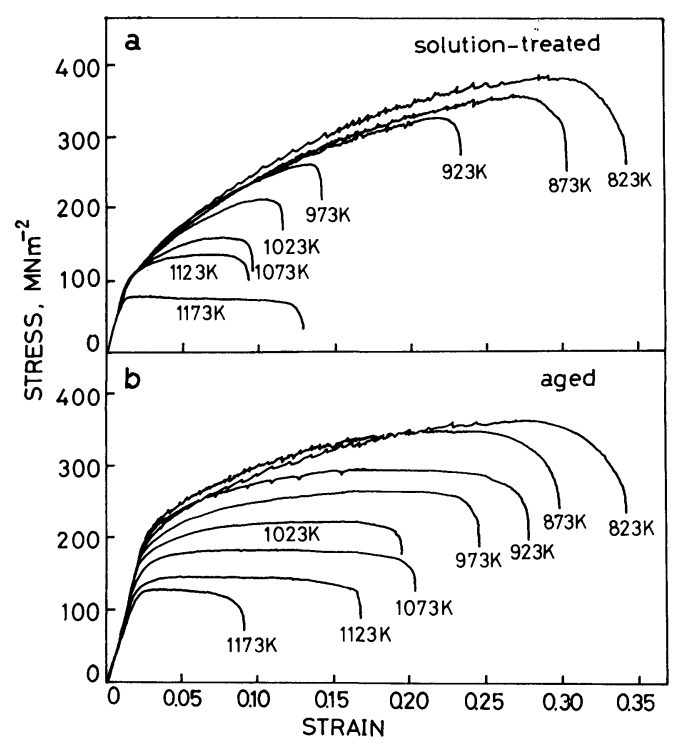

(a) Solution-treated specimen

(b) Aged specimen

Fig. 1. Stress-strain curves. aged in all the temperature range examined, and the rates for both specimens decrease with increasing deformation temperature above $900 \mathrm{~K}$.

\section{Fractography}

Photograph 1 shows the effect of deformation temperature on the fracture mode of the solution treated specimen. Large dimples arising from transgranular ductile fracture can be seen in the specimen deformed at $873 \mathrm{~K}$, while the fraction of intergranular fracture increases with raising deformation temperature (Photo. 1(b)). The detailed examination of the intergranular facets reveals that they can be classified into two types: the intergranular facets with small dimples at $1073 \mathrm{~K}$ and those with wavy wrinkles at $1173 \mathrm{~K}$ as in Photos. 1(c) and (d), respectively. Such wavy patterns on the intergranular facets tend to increase with increasing deformation temperature.

Photograph 2 shows the effect of deformation

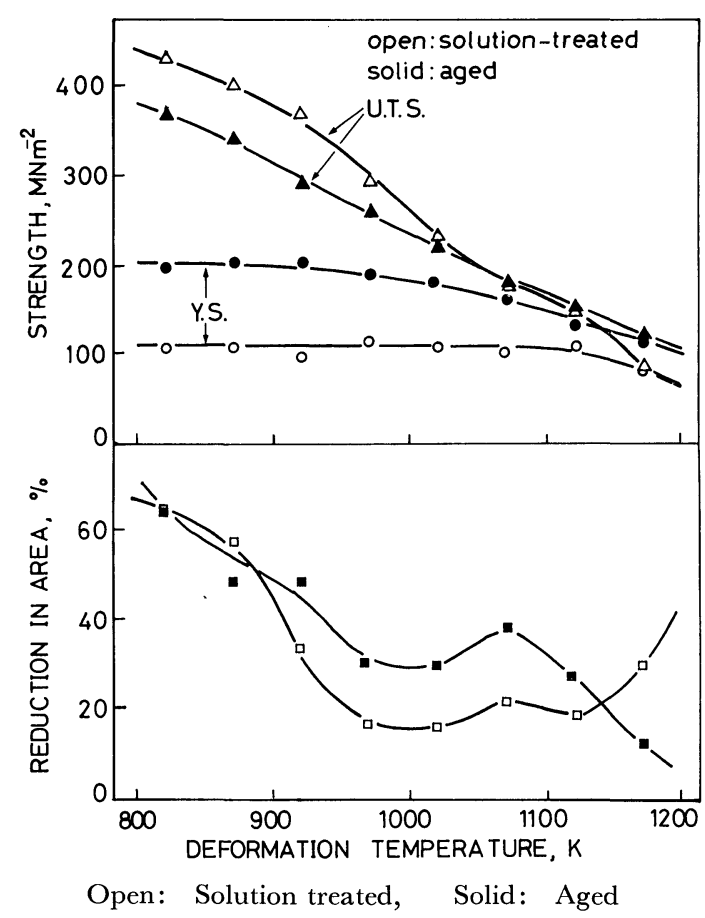

Fig. 2. Variation of tensile properties with deformation temperature.

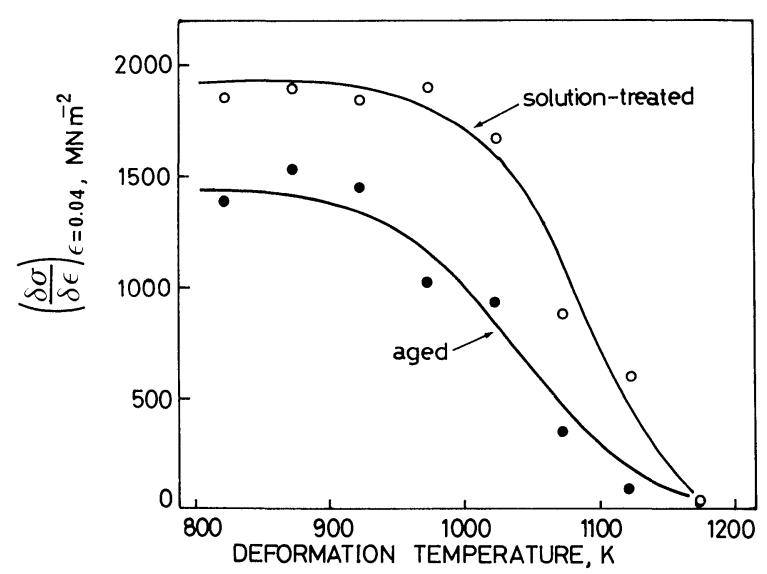

Fig. 3. Variation of work hardening rate with deformation temperature. 

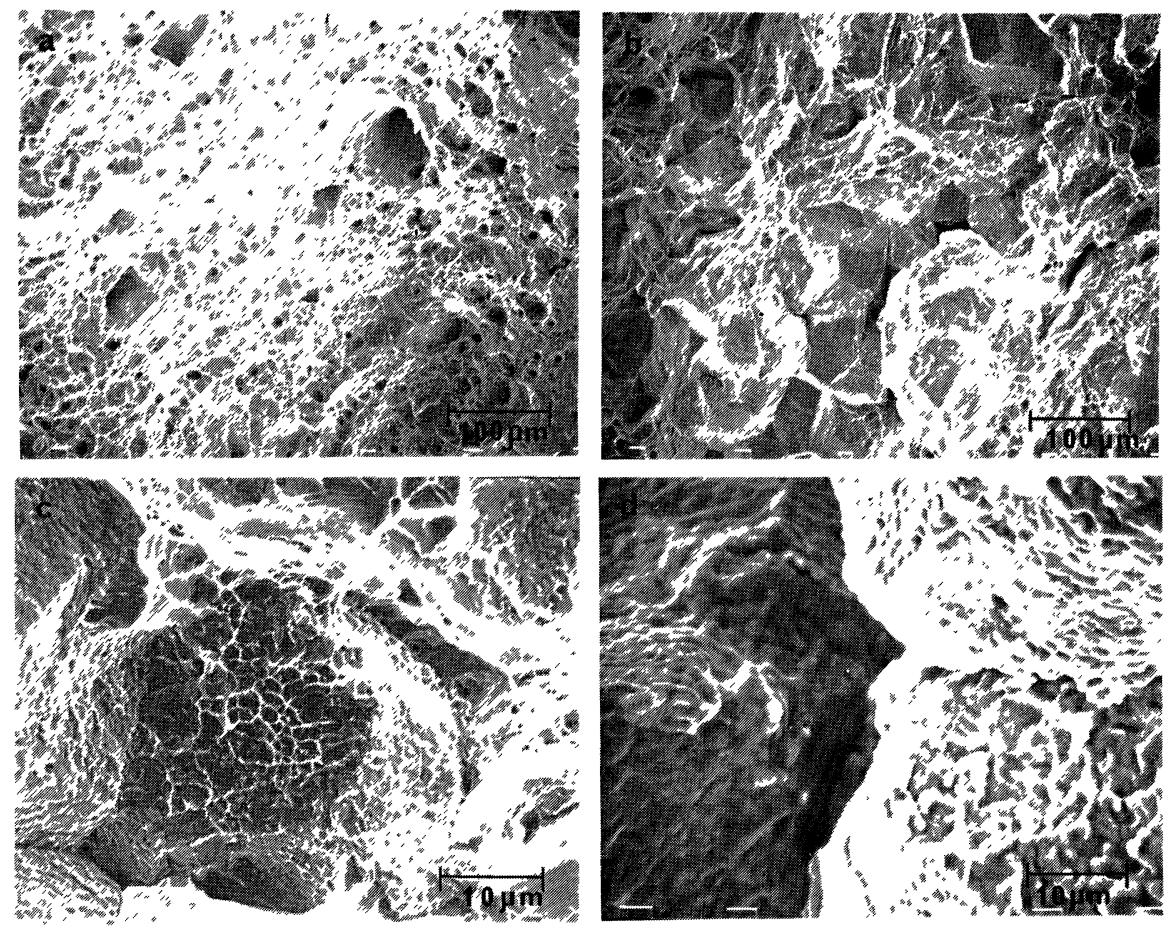
(a) $873 \mathrm{~K}$
(b) $973 \mathrm{~K}$
(c) $1073 \mathrm{~K}$
(d) $1173 \mathrm{~K}$

Photo. 1. Fracture surface of the solution-treated specimen.
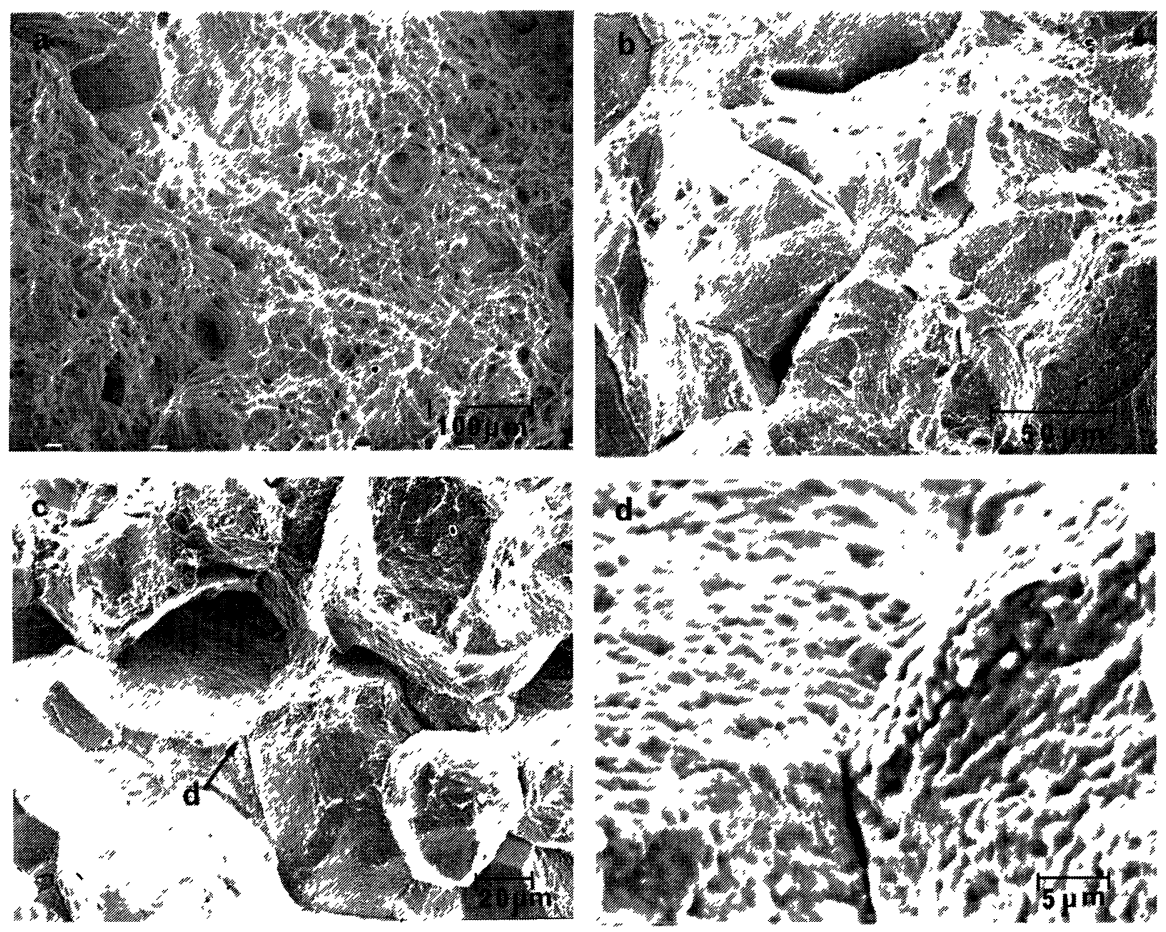

(a) $873 \mathrm{~K}$

(b) $1073 \mathrm{~K}$

(c) $1173 \mathrm{~K}$

(d) $1173 \mathrm{~K}$

Photo. 2. Fracture surface of the aged specimen.

temperature on the fracture mode of the aged specimens. The specimens deformed at temperature below $873 \mathrm{~K}$ show the transgranular mode of fracture similar to that of the solution treated (Photo. 2(a)), and the fraction of intergranular fracture increases with raising deformation temperature. Although some transgranular ductile facets are observed in the specimen deformed at $1073 \mathrm{~K}$ (Photo. 2(b)), fracture mode in the specimen deformed at temperatures above $1123 \mathrm{~K}$ is mostly intergranular as in Photo. 2(c), and wavy wrinkles can be observed on the intergranular facets (Photo. 2(d)). 


\section{Metallography}

The grain size of the solution treated specimen was rather coarse and the mean linear intercept of the boundaries was $83 \mu \mathrm{m}$. Photograph 3 shows the microstructures of the aged specimen. Rather coarse $\mathrm{M}_{23} \mathrm{C}_{6}$ particles are formed discretely on the random grain boundaries as in Photos. 3(a) and (b). These $\mathrm{M}_{23} \mathrm{C}_{6}$ particles exhibit the cube-cube crystallographic orientation relationship with one of the $r$ grains, and grow into the other grain without any relationship as can be seen in the dark field image (Photo. 3(b)). While particles formed on the incoherent twin boundaries are much finer in size as in Photo. 3(c) and the precipitates cannot be observed on the coherent twin boundaries. It is interesting to note that a number of stacking faults with $\mathrm{NbC}$ precipitation forms closely to the coherent twin boundaries as Photo. 3(d).

Fine $\mathrm{NbC}$ particles also precipitate on the dislocations introduced by the growth of $\mathrm{M}_{23} \mathrm{C}_{6}$ particles as indicated by arrows in Photo. 3(b). Although NbG particles can be observed on neither the random boundary nor the incoherent twin boundaries, they frequently form on the coherent twin boundaries.

Photograph 4 illustrates an example of close examination of the stacking faults with $\mathrm{NbC}$ precipitates. Four different variants of stacking faults can clearly be recognized. From the dark field illumination with using a $\{111\}_{\gamma}$ and a $\{111\}_{\mathrm{NbC}}$ reflections, these stacking faults were confirmed to be parallel to the $\{111\}$ planes (Photo. 4(b)). Each austenite grain is divided into much smaller regions by these stacking faults. High density of fine $\mathrm{NbC}$ particles on the stacking faults can be seen. It should be noted that the diffraction contrast from some parts of the stacking faults disappears and only the weak thickness fringes due to the $\mathrm{NbC}$ particles on the
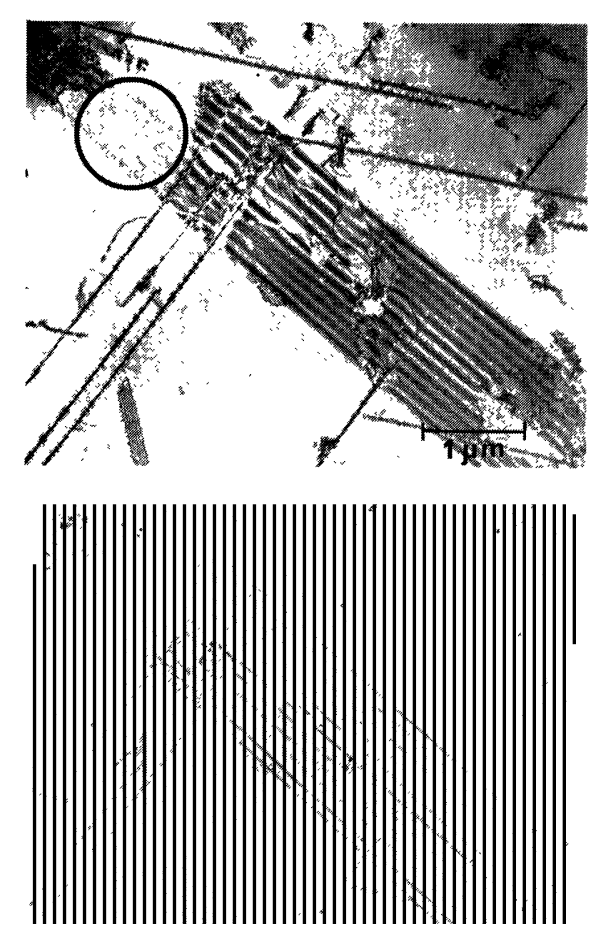

(a) Bright field image (b) Dark field image

Photo. 4. TEM micrographs showing the stacking fault precipitation in the aged specimen.
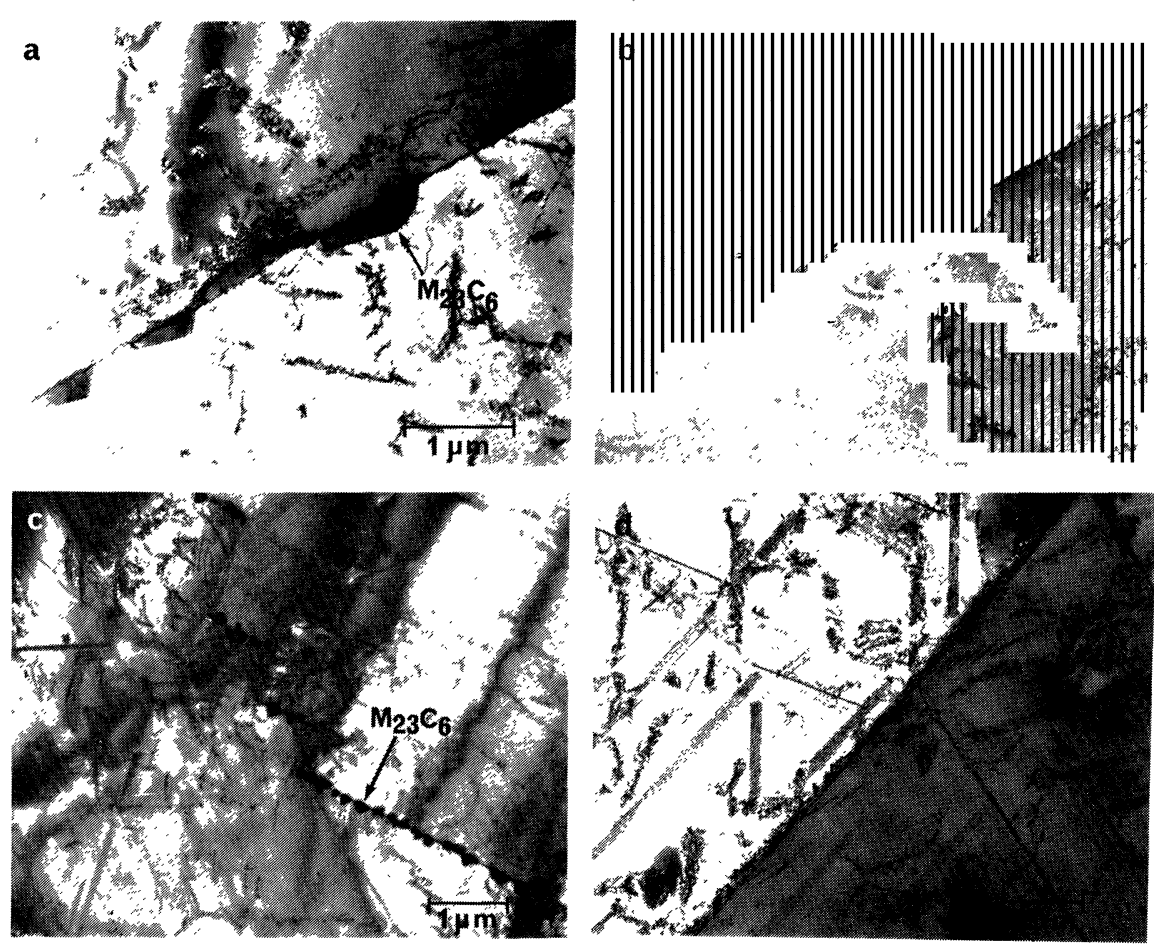

(a), (b) Random grain boundary

(c) Twin boundary

(d) Coherent twin boundary

Photo. 3. TEM micrographs showing $\mathrm{M}_{23} \mathrm{C}_{6}$ and NbG precipitations at grain boundaries in the aged specimen. 
previously existed stacking faults can be seen as indicated by circle in Photo. 4(a).

Photographs 5 to 7 show the microstructures of the solution treated specimen deformed at 873, 1073 and $1173 \mathrm{~K}$, respectively. In the specimen deformed at $873 \mathrm{~K}$, stacking faults form frequently with high density of dislocations, and no precipitates can be observed (Photo. 5). The deformation at $1073 \mathrm{~K}$, where deep ductility trough appears, produces very fine $\mathrm{NbC}$ particles precipitated dynamically on the dislocations within the grains and rather coarse particles on the grain boundaries with the precipitation free zones (PFZ's) along them as in Photos. 6(a) and (b). Photographs 6(c) and (d) show the trace of grain boundary migration. The dark field image using a reflection from the grain in the lower part in Photo. 6(c) indicates that the $\mathrm{NbC}$ particles within the upper grain aligned almost parallel to the boundary and were in the cube-cube orientation relationship ${ }^{12)}$ with the lower grain (Photo. 6(d)). This suggests that the particles had formed on the grain boundary at the initial position in contact with the lower grain and then the boundary migrated with leaving the row of the precipitates.

In the specimen deformed at $1173 \mathrm{~K}$, a typical recovered structure consisting of dislocation networks can be observed as in Photo. 7 .

Photograph 8 shows the microstructure of the aged specimen deformed at $873 \mathrm{~K}$. In this case the dislocation density is quite high and formation of dislocation cell structures can be clearly seen. The stacking faults were observed to meander due to the deformation (the arrow in Photo. 8(a)).

Although small amounts of dynamically precipitated $\mathrm{NbC}$ can be seen within the grains in the specimens deformed at higher temperatures, most of the precipitates are on the stacking faults which formed prior to the deformation similarly to the case of

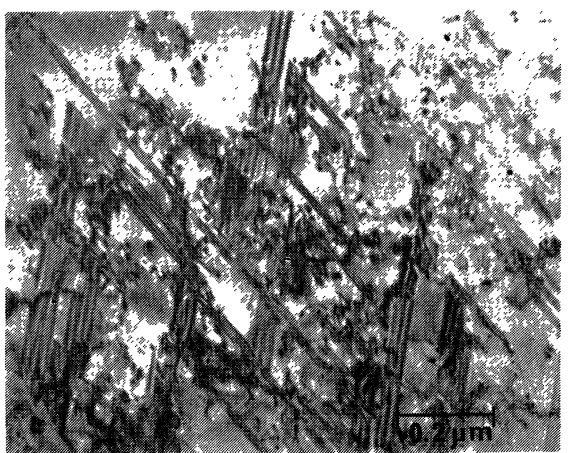

Photo. 5. TEM micrograph of the solution-treated specimen deformed at $873 \mathrm{~K}$.

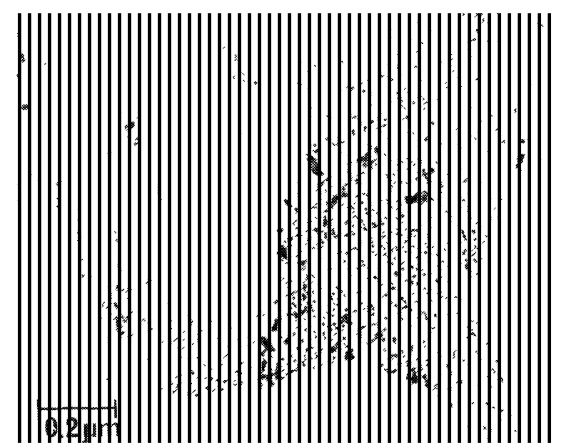

Photo. 7. Dislocation network of solution-treated specimen deformed at $1173 \mathrm{~K}$.
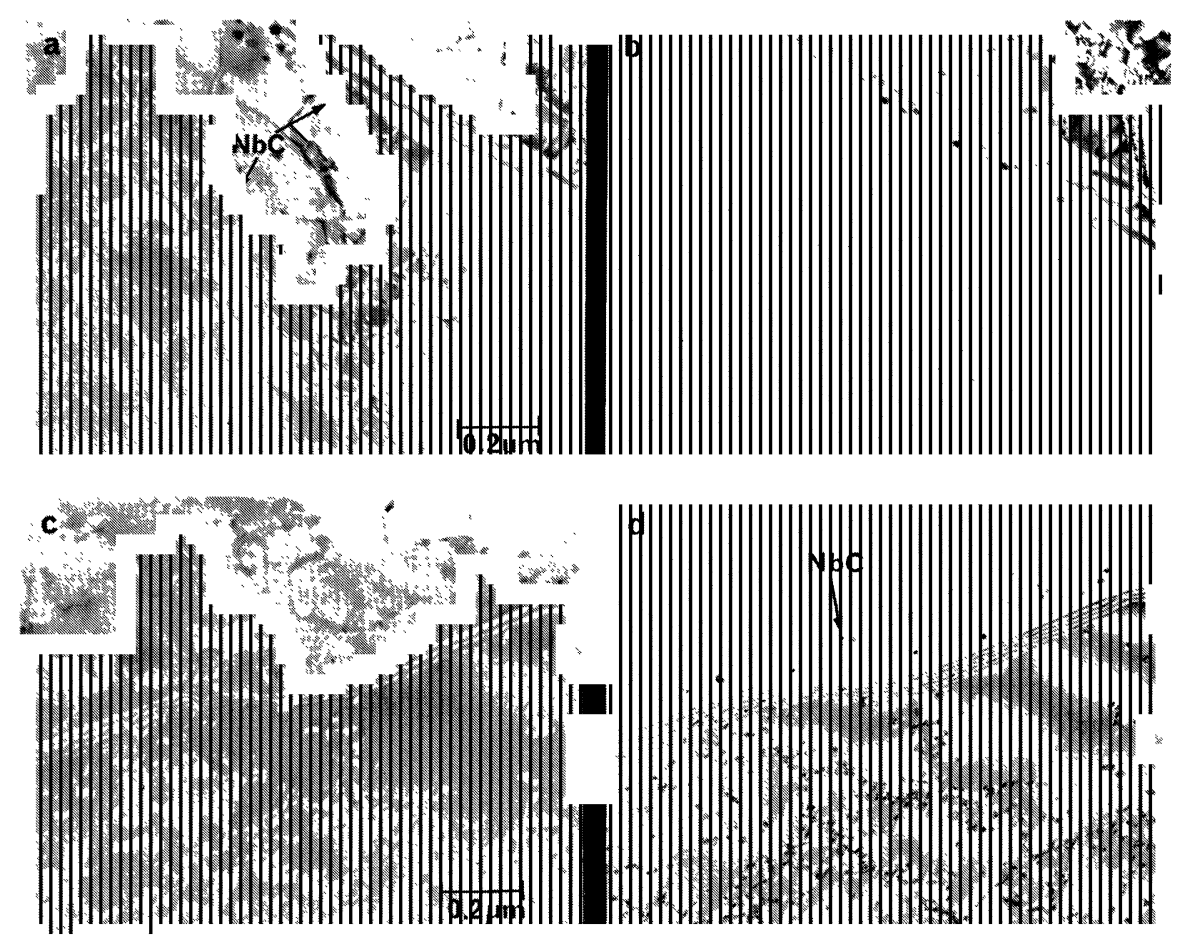

(a), (c) Bright field image

(b), (d) Weak-beam dark field image

Photo. 6. NbC precipitation at random grain boundary (a, b) and at twin boundary (c, d). 
deformation at $873 \mathrm{~K}$ (Photo. 9). It should be noted that the dislocation density of the specimen fractured at $1173 \mathrm{~K}$ was quite low because the final fracture occurred at the early stage of straining.

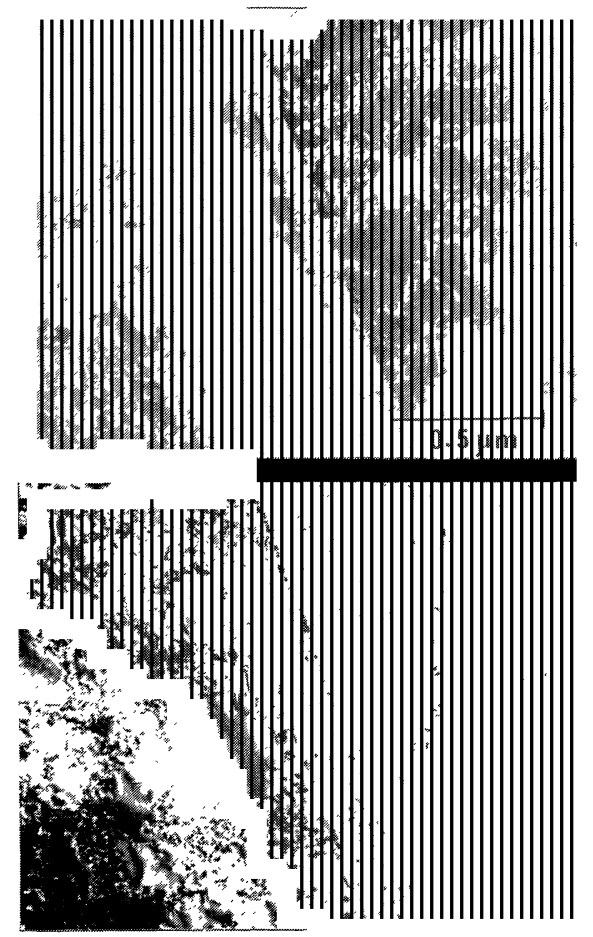

(a) Bright field image (b) Dark field image

Photo. 8. Deformation structure of the aged specimen deformed at $873 \mathrm{~K}$.
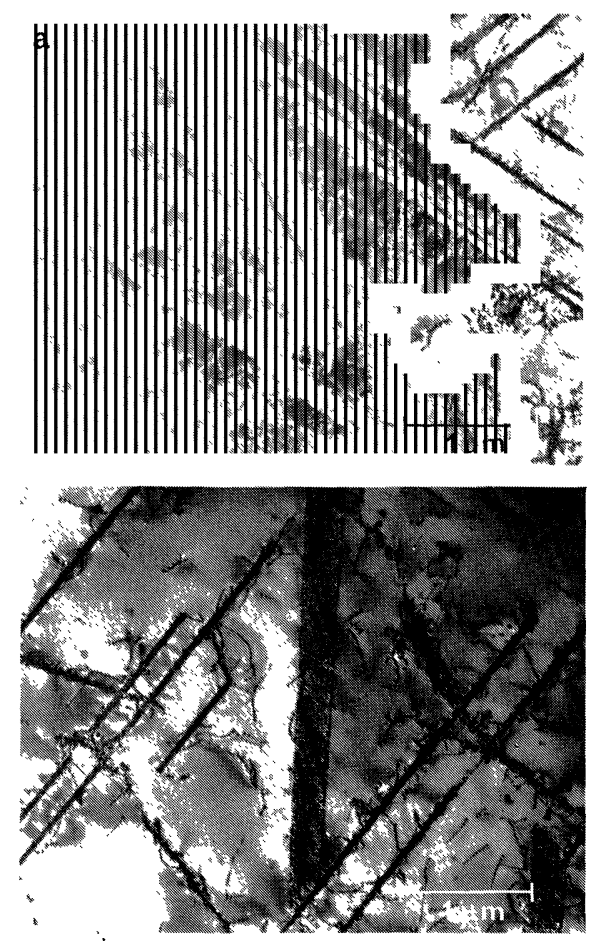

(a), (c) Bright field image

\section{Discussion}

1. $\mathrm{M}_{23} \mathrm{C}_{6}$ and $\mathrm{NbC}$ Precipitation during Aging

Aging at $973 \mathrm{~K}$ after the solution treatment at $1523 \mathrm{~K}$ yields both $\mathrm{M}_{23} \mathrm{C}_{6}$ and $\mathrm{NbG}$ precipitations within the grains as well as on the grain boundaries. The preferential nucleation site for $\mathrm{M}_{23} \mathrm{C}_{6}$ is of course the random grain boundaries, but the coherent twin interfaces are almost free from the precipitates as already reported by other investigations. ${ }^{13,14)}$ Whereas $\mathrm{NbG}$ particles do not precipitate on the grain boundaries except the coherent twin interfaces and majority of them is in the form of the stacking fault precipitation within the grains. These facts suggest that $\mathrm{M}_{23} \mathrm{C}_{6}$ particles can precipitate more easily at the incoherent grain boundaries than $\mathrm{NbC}$ particles, and that, once $\mathrm{M}_{23} \mathrm{C}_{6}$ particles nucleate, their growth will continuously consume $\mathrm{G}$ atoms in the vicinity of the boundaries, which may suppress precipitation of $\mathrm{NbC}$. It is also interesting to note that the stacking fault precipitation of $\mathrm{NbC}$ particles cannot be observed in the vicinity of the random grain boundaries where the precipitation of $\mathrm{M}_{23} \mathrm{C}_{6}$ particles likely occurs prior to that of $\mathrm{NbC}$ (Photos. 3(a), (b)). This indicates that depletion of $\mathrm{Cr}$ atoms by precipitation of $\mathrm{M}_{23} \mathrm{C}_{6}$ particles increases the stacking fault energy and suppresses the stacking fault precipitation of $\mathrm{NbC}$. In fact, the formation of PFZ along the boundaries supports this model. Such effects of alloying elements on the stacking fault precipitation have already been reported by Harding and Honeycombe ${ }^{5)}$ and Silcock et al., ${ }^{15)}$ who demonstrated that the addition of $\mathrm{U}$ or $\mathrm{Si}$ accelerates the stacking fault precipitation in the austenitic stainless steels by lowering the stacking fault energy.
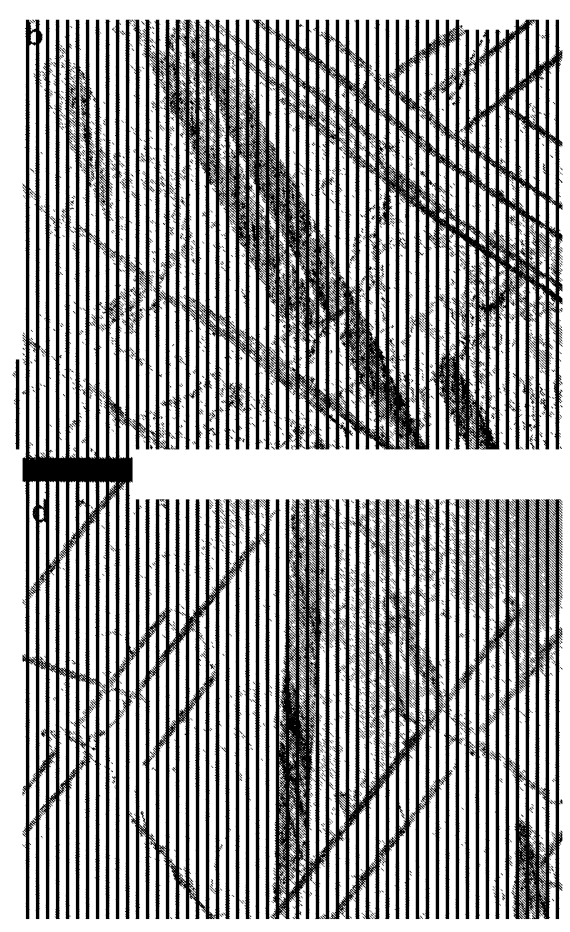

(b), (d) Weak-beam dark field image

Photo. 9. Deformation structure of the aged specimen at $1073 \mathrm{~K}$ (a, b) and $1173 \mathrm{~K}$ (c, d). 


\section{Effects of $\mathrm{NbC}$ Precipitation on Tensile Properties}

The aged specimen exhibits much higher yield strength due to the stacking fault precipitation of $\mathrm{NbC}$ at temperatures below $1050 \mathrm{~K}$. Dispersion of NbG particles in this case, however, is quite inhomogeneous, and the mean interparticle spacing is quite large, $0.5 \sim 1 \mu \mathrm{m}$, thus the strengthening cannot be explained in terms of Orowan's mechanism which strongly depends on the interparticle spacing. It should be noted that stacking faults with densely distributed $\mathrm{NbC}$ particles can act as hard platelets within the grains. These platelets, lying on four $\{111\}$ planes, will separate a grain into much smaller regions as has been suggested by Harding et al.,5) and will act as the barriers for dislocation motion. In fact, a number of dislocations clinging to these faults can frequently be observed (Photos. 8 and 9). It has commonly be accepted that flow stress during small strain rate deformation at elevated temperatures can be determined mainly by the average size of either subgrains or recrystallized grains forming during deformation and that the initial grain size dependence of flow stress is less significant. In the case of yielding at temperatures where the recrystallization does not occur, however, the initial grain size should dominate the yield stress because the subgrains have not well developed when yielding initiates. Thus it is of interest to argue the increase of yielding stress with the grain size effect. If the areas separated by the hard platelets of stacking fault precipitation can act as small grains, the yield stress increase can reasonably be explained by Hall-Petch relationship ${ }^{16,17)}$ since the effective grain size, $0.91 \mu \mathrm{m}$, is about $10^{-2}$ times smaller than the grain size of the solution treated specimen.

The work hardening rates of the solution treated specimen at temperature between $900 \mathrm{~K}$ and $1100 \mathrm{~K}$ on the other hand are much larger than those of the aged specimens. This is probably due to the dynamic precipitation of $\mathrm{NbC}$ particles, i.e., the dislocations nucleating at the grain boundaries will be subsequently pinned by the fine precipitation of $\mathrm{NbC}$ particles on them and further dislocation multiplication will be required to continue the deformation, resulting in a marked increase of dislocation density. In the aged specimens, on the other hand, such effect of dynamic precipitation is negligibly small, because most $\mathrm{NbC}$ particles have precipitated in the form of the stacking fault precipitation prior to the deformation. Therefore the dislocations emerging at the boundaries will be hardly pinned down by fine $\mathrm{NbC}$ particles and can move more freely. This will lead to the small work hardening.

Hot ductility is also closely related to the precipitation of NbC. In the solution treated specimens the ductility is reduced by the deformation at temperature ranging from 950 to $1150 \mathrm{~K}$. This ductility trough can be explained as follows.

Since the matrix is strengthened by the dynamic precipitation of fine $\mathrm{NbC}$ particles, the strain will concentrate within the softer PFZ's along the grain boundaries. Then microvoids will be formed by the decohesion of the interfaces between the matrix and the coarse precipitates such as $\mathrm{M}_{23} \mathrm{G}_{6}$ and $\mathrm{NbC}$ on the boundaries. The coalescence of them will lead to intergranular ductile fracture in keeping with the observation in Photo. 1(c). In the aged specimens, the ductility trough is rather shallow. This can be explained mainly by the decrease of $\mathrm{NbC}$ dynamic precipitation, because of static stacking fault precipitation of $\mathrm{NbC}$ prior to the deformation.

Although the ductility of the solution treated specimens is improved by raising the deformation temperature up to $1173 \mathrm{~K}$, that of the aged specimens is markedly reduced above $1123 \mathrm{~K}$, which accompanies with the increase in fraction of the intergranular fracture along the original boundaries. The detailed mechanism for it is not clear at present, but it is probably due to the dynamic recrystallization in the vicinity of the grain boundaries. The intergranular mode of fracture with wavy wrinkles may be the results of such a microstructural change near the grain boundaries.

\section{Conclusions}

(1) Although the yield strength of the solutiontreated specimen is quite low, remarkable work hardening occurs during the deformation at temperature ranging from 1023 to $1123 \mathrm{~K}$. In this temperature region, deep ductility trough accompanying the intergranular ductile mode of fracture is observed. These facts can be explained in terms of the dynamic precipitation of NbG within the grains, the PFZ's formation and the grain boundary precipitation of coarse $\mathrm{M}_{23} \mathrm{C}_{6}$ and NbC particles.

(2) The yield strength of the aged specimen is considerably higher than that of the as-solutiontreated specimen but the work hardening rate during the deformation is less significant. The increase of the yield strength by aging can be explained by the decrease in the effective grain size by the presence of the platelets comprising the stacking fault precipitation of fine NbC particles. The ductility trough in this case is rather shallow because of the decrease of the dynamic $\mathrm{NbC}$ precipitation.

(3) At temperatures above $1123 \mathrm{~K}$ the ductility of the solution-treated specimen increases with increasing deformation temperature, but that of the aged specimen is largely reduced. This is probably due to the microstructural change in the vicinity of the grain boundaries.

\section{Acknowledgements}

The authors would like to thank Dr. K. Nishioka, General Manager and Director of Central Research Laboratories, Sumitomo Metal Industries, Ltd., for permission to publish this article and indepted to Dr. F. Terasaki for his valuable advices during the course of this study.

\section{REFERENGES}

1) Y. Maehara and Y. Ohmori: Mat. Sci. Eng., 62 (1984), 109.

2) Y. Ohmori and Y. Maehara: Trans. Japan Inst. Metals, 25 (1984), 160. 
3) I. Weiss and J. J. Jonas: Met. Trans., 10A (1979), 831.

4) J.S.T. Aswegen and R.W.K. Honeycombe: Acta Met., 10 (1962), 262.

5) H. J. Harding and R.W.K. Honeycombe: JISI, 204 (1966), 259.

6) R. D. Naybor: JISI, 204 (1966), 1200.

7) J. P. Adamson and J. W. Martin: Proceeding of a Meeting on 'Creep Strength in Steel and High-temperature Alloys', Metals Soc., London, (1972), 106.

8) J. M. Silcock and W. J. Tunstall: Phil. Mag., 10 (1964), 361 .

9) J.S.T. Aswegen, R.W.K. Honeycombe and D. H. Warrington: Acta Met., 12 (1964), 259.
10) J. Barfold: JISI, 204 (1966), 134

11) T. Thorvalsson and G. L. Dunlop: Met. Sci., 14 (1980), 513.

12) D. M. Haddrill, R. N. Younger and R. G. Baker: Acta Met., 9 (1961), 982.

13) U. E. Wolff: Trans. AIME, 236 (1966), 207.

14) M. H. Lewis and B. Hattersley: Acta Met., 13 (1965), 1159.

15) J. M. Silcock, K. W. Sidding and T. K. Fry: Met. Sci. J., 4 (1970), 29

16) E. O. Hall: Proc. Phys. Soc., B64 (1951), 747.

17) N. J. Petch: JISI, 173 (1953), 25. 